\title{
A survey on occurrence of internal and external fish parasites and causes of fish population reduction in Lake Hashenge, Tigray, Ethiopia
}

\author{
Abreha Tesfaye ${ }^{1}$, Awot Teklu*, Tilaye Bekelle, Tsegay Tkue, Etsay Kebede, Teklit Ge- \\ bretsadik $^{2}$, and Netsanet Berhe ${ }^{1}$ \\ ${ }^{1}$ College of Veterinary Medicine, Mekelle University. \\ ${ }^{2}$ College of Health Science, Mekelle University. \\ "Corresponding author email: awetina95@yahoo.com / awot.teklu@mu.edu.et \\ https: / /dx.doi.org/10.4314/evj.v21i2.6
}

\begin{abstract}
A cross-sectional study was conducted from November 2015 to June 2016 to determine the occurrence of internal and external parasites in wild fish population of Lake Hashenge and identify the causes of the trends in reduction of fish population. A total of 125 randomly selected fish samples comprising 122 (97.6\%) Nile tilapia (Oreochromis niloticus) and 3(2.4\%) T. zilli were examined for internal helminthes and external parasites. Overall, 37.6\% (47/125) of fish were infested by internal parasites (adults or eggs/larva) while none of them were infested with external parasites. The internal parasites recovered were Clinostomum, Acanthocephalues and Capillaria accounting for 15.2\%, 11.2\%, and $7.2 \%$ of the total infection respectively, while $4 \%$ had mixed infection. Moreover, the distribution of parasitic genera were found to be significantly different $(p<0.05)$ with respect to sex, weight, and lengths of the sampled fish, in that females ( $\mathrm{n}=48,24.8 \%)$, fish with body weight 500-1000g $(\mathrm{n}=89,30.4 \%)$, and length $20-40 \mathrm{~cm}(\mathrm{n}=68,22.4 \%)$ were found to be more infected. Most of the respondents (92\%) indicated a great reduction in the water and the fish population of the lack from its previous state. All of the respondents have stated that residents of the area wash their clothes in the Lake using synthetic and/or natural detergents and $86 \%$ of the respondents believed that Lake Hashenge receives flooding water from nearby uphills and the people use the water from the Lake for small scale irrigation purposes. These findings demand a future focus and stretch of intervention programs for alleviation of the problems facing the Lake before its exhaustion.
\end{abstract}


Keywords: Fish; Lake Hashenge; Parasites; Prevalence; Population reduction.

\section{Introduction}

Fish production in Ethiopia was not pronounced whatever food scarcity existed (Rothuis et al., 2012). However, since the end of the eighties, the government placed emphasis towards the development of the sector with ultimate goal of self-food sufficiency. For this reason, the Ethiopian government has recently established a "Ministry of Livestock and Fishery Resources" in October, 2015 for the proper utilization and sustainability of the sector (MOA, 2015). Despite the focus given to the sector's development, the Ethiopian fishery is being faced with a number of biotic and/or abiotic constraints that have affected the productivity and sustainability of the sector (Abadi Amare et al., 2014; FAO, 2014).

The prevalence of biotic infectious pathogenic parasites are among the most important causes hampering the production and productivity of the fishery sector (Assefa Mitike, 2014; Emaminew Tizie et al., 2014). Fish parasites result in huge economic losses as they increase mortality; increase expenses or farm inputs through increased treatment expenses, and cause reduction in growth rate and weight loss during and after the period of parasitic disease outbreak. All of these militate against the quality and productivity of the produce leading to its condemnation or consumer rejection (Kayis et al., 2009). Several groups of parasites belonging to helminthes, arthropods, protozoan and others of miscellaneous taxa are known to infect fish and produce harmful effects on their hosts (Emaminew Tizie et al., 2014; Yewubdar Gulelat et al., 2013).

To date, fewer studies have been so far conducted on fish parasites in some Lakes and reservoirs of Ethiopia, including Lake Tana (Emaminew Tizie et al., 2014), Lake Lugo (Abadi Amare et al., 2014), Koka reservoir (Yewubdar Gulelat et al., 2013), and Lake Ziway (Jossy Bekele and Daniel Hussien, 2015). Findings included: Six parasitic species belonging to Nematodes (Contracecum, Camallanus, and Eustrongylides species), Cestodes (Ligula intestinalis and Proteocephalus species), and Trematodes (Clinostomum spp.), of different taxonomic groups with an overall prevalence of $20.83 \%$ on Lake Ziway, $47.43 \%$ on Lake Hyke, and $29 \%$ on Lake Tana from different fish species including Tilapia, Cat fish (Clarias), Lates, Barbus, Bagrus, Labeo spp., and others (Abadi 
Amare et al., 2014; Jossy Bekele and Daniel Hussien, 2015; Yewubdar Gulelat et al., 2013).

In addition to the overall effect of the biotic pathogens, a number of abiotic (environmental and/or human-made) factors have also been reported to hinder the production and productivity of the fishery sector and question its sustainability. Factories, agriculture and sewage are the sources of major pollutants affecting the Ethiopian water bodies and their aquatic resources. For instance, the current extraction of minerals from Lake Abijata; the effluents from the tannery factory at Koka Reservoir; and the textile industries at Hawassa and Arba Minch are among the abiotic factors reported to cause reduction in fish catches and disappearance of some species (Abadi Amare et al., 2014; Jossy Bekele and Daniel Hussien, 2015; Yewubdar Gulelat et al., 2013). Furthermore, the increasing rate of deforestation could result in increased drying up of water bodies and increase in water turbidity and, hence, a negative effect on the aquatic flora and fauna (Gebreselassie Asgedom et al., 2012; Lmenew Yared et al., 2009). Hence, regular screening of all the water bodies of the country for the causes of any trending reduction in fish population and productivity, and for the existence of pathogenic parasites is important for an optimum quality and quantity of wholesome product harvested and sustainability of the sector.

Lake Hashenge, the study Lake, is a small highland lake in the southern zone of the Tigray regional state's Ofla woreda. The Lake, being the only closedhighland lake in the region, has been so far vigorously exploited and serving as a crucial source of fishmeat, some irrigated-agriculture and source of drinking water for animals. It produces on average of seven to ten tons of fish annually with a predicted annual potential of about 25-30 tons (TBARD, 2010; Lmenew Yared et al., 2009). However, reports and personal observation have shown that there is drastic decrease in fish population and downgrade in the quality and quantity of the Lakes's water.

So far, in a preliminary study carried out by Haftom Abay and Etsay Kebede, (2007) have found an overall prevalence of $8.61 \%$ of helminth fish parasites in fish sampled from Lake Hashenge. However, there are no recent works carried out on the species identification of fish parasites and their importance, and on the possible causes for the trending reduction in fish population of the lake. Hence, the present study was conducted so as to identify and asses on 
the prevalence of fish parasites, and to investigate on the possible humanassociated factors associated with fish population reduction of Lake Hashenge.

\section{Materials and Methods}

\section{Study area}

Lake Hashenge is located in Ofla district of the southern administrative zone of Tigray Region in the Northern highlands of Ethiopia at about $628 \mathrm{Km}$ north of Addis Ababa (Figure 1). The lake has coordinates of $12^{\circ} 34^{\prime} 50^{\prime \prime} \mathrm{N}$ longitude and $39^{\circ} 30^{\prime} 00^{\prime \prime} \mathrm{E}$ latitude, an elevation of 440 m.a.s.l, and receives an annual average rainfall of 600-800 $\mathrm{mmHg}$ (Gebreselassie Asgedom et al., 2012). This lake has no any outlet to drain its water contents.

Lake Hashenge is about $5 \mathrm{Km}$ long and $4 \mathrm{Km}$ wide, with an average surface area of $20 \mathrm{Km}^{2}$. It has a drainage area of $129 \mathrm{Km}^{2}$ and a maximum depth of $25 \mathrm{~m}$. As part of the surface water source, the lake is the only closed high altitude lake in the region and can support the economic growth of the region through irrigated agriculture and fishery produce (TBARD, 2010).

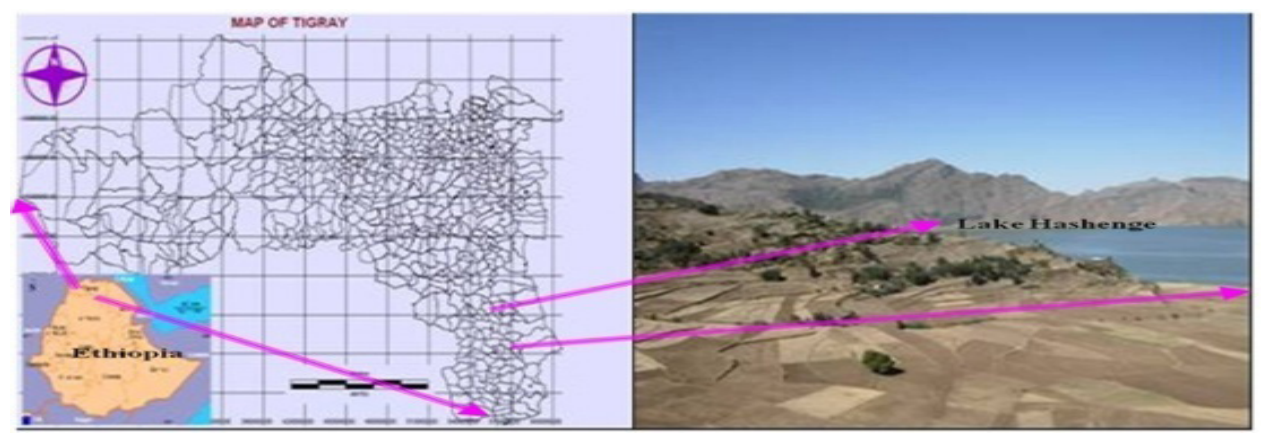

Figure 1. Map and image of Lake Hashenge in Tigray region, Northern Ethiopia (Gebreselassie Asgedom et al., 2012).

\section{Study design and study population}

A cross-sectional study was conducted on fish population of Lake Hashenge to identify and assess on the prevalence of internal and external parasites infesting fishes and determine the possible causes for the trends in fish population reduction. The fish population that inhabit the Lake were so far reported to be the Nile Tilapia (Oreochromis niloticus), Tilapia zillii, the African cat fish 
(Clarias gariepinus) and Barbus spp. with the Nile Tilapia being the dominant population. However, due to the extreme reduction in the fish population of the Lake, only Nile tilapia and Tilapia zilli were included in the current study. Neither African cat fish nor the Barbus spp. were reachable for sampling during the study period.

\section{Sample size and sampling technique}

According to a study carried by Haftom Abay and Etsay Kebede (2007), a total prevalence of $8.61 \%$ of fish parasites have been documented from intestinal contents or feces of fish from Lake Hashenge. Hence, taking the Thrusfield's formula (Thrusfield, 2005) into consideration and an expected prevalence of $8.61 \%$, a maximum of 125 fishes were sampled using systematic random sampling method for both internal and external parasitic identification in the current study. For the calculation, a $95 \%$ level of confidence and $5 \%$ absolute precision were used.

\section{Sample collection, transport and handling}

A total of 125 fish samples were bought following their harvest and rapped within small transparent plastic bags and immediately transported in icebox to the Parasitology Laboratory of the College of Veterinary Medicine, Mekelle University for their parasitological examination. The species, sex, possible sites of infestation, body weight, total and standard lengths of individual fish were initially assessed and recorded. The fish body weights and lengths were categorized into classes based on classification as described by Gebreselassie Asgedom et al (2012). An individual plastic bag was labeled with numbers for easier identification of samples and traceability of any associated findings. All the fish were caught using a fixed gill net with mesh size ranging from 60 to $120 \mathrm{~mm}$ that was used for exploratory and business fishing work at the Lake carried by the Fishermen Associations. All specimens were immediately examined in less than an hour period of their arrival to the laboratory prior to their spoilage and/or damage of any anatomical structures.

\section{Postmortem examination and parasite identification}

First of all, each sampled fish was externally visualized, palpated and examined for any ecto-parasites on the entire fish skin, the fins and opercular cavity including the gills. Post mortem examination was, then after, carried out employing a standard evisceration procedure as described by Zhokhov et al 
(2007). Briefly, the whole body cavity was opened and examined for parasites in the intestinal tract and other sites including the muscles. The gill filaments and various organs including stomach, intestine, liver, heart, gall bladder and gonads were removed and placed separately in Petri dishes containing $0.75 \%$ saline solution. First, the external surface of each organ was examined and then each organ was opened for examination of parasites.

The gastro-intestinal lumen was opened by making an incision along its length and examined for presence of any adult parasites. Conjointly, intestinal contents or fecal samples were collected on universal bottles for examination of parasitic eggs. Direct smear, floatation, and sedimentation techniques have been carried out to isolate parasite eggs based on their specific gravity. The egg isolation, characterization and identification procedures were done according to Urquhart et al (2003).

All the collected parasites were preserved in $70 \%$ ethanol and fixed in glycerine for further identification. The parasites were then identified under stereomicroscope using the identification guideline as stated by Paperna (1980).

\section{Questionnaire survey}

A questionnaire survey was carried out so as to asses for any biotic (human associated) factors contributing to fish population reduction or to any ill-effect in the overall ecosystem of Lake Hashenge. Accordingly, a pre-tested semi-structured questionnaire format was prepared to obtain general information on the demographic characteristics (age, sex, marital status, educational status etc.) of respondents dwelling the vicinity of the Lake, and so as to gather information on the overall trending status of fish population and ecosystem of the Lake (quantity and type of fish population harvested, its trending size, the physical quality of the water), and on the way the dwelling community handle or use the Lake (manner of fishing practice, use of water for washing activities).

A total of 100 respondents were considered for the current study using the single population formula and taking into account the population size of the three peasant associations around the Lake as described by Yamene (1995). Technically, a stratified simple random sampling technique was used so as to ensure the adequate sample size of respondents from the specified study site. Randomly sampled respondents were stratified based on their age differences, living and occupational status, and educational levels. Focus Group Discus- 
sions (FGDs) and Key Informant Interviews (KIs) were the main data collection techniques used in the study. Moreover, informal observations of target sites and study communities were also included as strengthening part of the questionnaire survey.

\section{Data management and analysis}

All the data obtained from the study were analyzed using SPSS statistical software (version-17). Accordingly, descriptive statistics including frequencies, percentages and the chi-square were used for possible explanation of associations to the prevalence of parasites and/or their eggs/larvae between the selected variables (body weight, length, sex and fish species) for sampled fish. P-values lesser than 0.05 were considered to be statistically significant at $95 \%$ confidence interval.

\section{Results}

\section{Prevalence of fish parasite}

Results of the current study have shown that there was no adult parasite (0\%) discovered but larvae and two types of eggs were recovered from the intestinal contents of fish through direct smear, floatation and sedimentation techniques. From the total of 125 sampled fish, Nile tilapia and T. zilli, 46(36.8\%) and $1(0.8 \%)$ of fishes were positive respectively with different parasitic genera (Table 1).

Table 1. The prevalence of helminth parasites in relation to the examined species of fish from Lake Hashenge.

\begin{tabular}{lcc}
\hline Fish species & Number of examined fish (\%) & Number of fish infected (\%) \\
\hline O. niloticus & $122(97.6 \%)$ & $46(36.8 \%)$ \\
Tilapia zilli & $3(2.4 \%)$ & $1(0.8 \%)$ \\
Total & $125(100 \%)$ & $\mathbf{4 7 ( 3 7 . 6 \% )}$ \\
\hline
\end{tabular}

In relation to sex and weight factors of the sampled fish, females had a statistically significant $(\mathrm{p}<0.05)$ higher prevalence of helminthes infection $(24.8 \%)$ than their counterparts (12.8\%). Similarly, the highest prevalence (30.4\%) was recorded in fish with body weight between $500-1000 \mathrm{~g}$, and the least (0.8\%) being in heavier fish of more than a kilogram weight. Likewise, the difference be- 
tween weight categories was also found to be statistically significant $(p<0.05)$ (Table 2).

Table 2. The prevalence of helminthes parasites in relation to sex and weight of the examined fish from Lake Hashenge.

\begin{tabular}{lcc}
\hline Factors & Number of examined fish (\%) & Number of fish infected (\%) \\
\hline Sex & & \\
Male & $77(61.6 \%)$ & $16(12.8 \%)$ \\
Female & $48(38.4 \%)$ & $31(24.8 \%)$ \\
Body weight (g) & & \\
$<500$ & $29(23.2 \%)$ & $8(6.4 \%)$ \\
$500-1000$ & $89(71.2 \%)$ & $38(30.4 \%)$ \\
$>1000$ & $7(5.6 \%)$ & $1(0.8 \%)$ \\
Total & $125(100 \%)$ & $47(37.6 \%)$ \\
\hline
\end{tabular}

Similarly, the prevalence of internal parasites was also evaluated based on the standard and total body lengths of the sampled fish. As a result, the highest prevalence (22.4\%) was significantly recorded for internal parasites in fish samples that are $20-40 \mathrm{~cm}$ long (Table 3 ).

Table 3. The prevalence of helminthes parasites in relation to the standard and total length of the examined fish from Lake Hashenge.

\begin{tabular}{lcc}
\hline Factor & Number of examined fish (\%) & $\begin{array}{c}\text { Number of fish } \\
\text { infected (\%) }\end{array}$ \\
\hline Total length $\mathbf{( c m )}$ & & \\
$<20$ & $0(0.00 \%)$ & $0(0.00 \%)$ \\
$20-40$ & $68(54.4 \%)$ & $28(22.4 \%)$ \\
$>40$ & $57(45.6 \%)$ & $19(15.2 \%)$ \\
Total & $125(100 \%)$ & $47(37.6 \%)$ \\
Standard length $\mathbf{( c m )}$ & & \\
$<15$ & $0(0.00 \%)$ & $0(0.00 \%)$ \\
$15-30$ & $26(20.8 \%)$ & $13(10.4 \%)$ \\
$>30$ & $99(79.2 \%)$ & $34(27.2 \%)$ \\
Total & $125(100 \%)$ & $47(37.6 \%)$ \\
\hline
\end{tabular}

Parasite distribution was also studied in relation to the sex and weight of the infected fish species. Accordingly, results revealed that there was statistically significant variation between the prevalence of the individual parasites and the variables with the highest infestation rate being recorded in Acantocephaleus 
in females (10.4\%) and Clinostomum (8\%) in males. Similarly, fish with body weight range of 500-1000 $\mathrm{g}$ were found to be with the highest parasitic infestation (30.4\%) with Clinostomum accounting for the highest parasitic share (15.2\%) (Table 4).

Table 4. Association between distributions of parasite genera with sex and weight of the infected fish species from Lake Hashenge.

\begin{tabular}{lccccc}
\hline Fish Species & Parasites Genera & \multicolumn{2}{c}{ Total } \\
\cline { 2 - 4 } & Clinostomum & Acanthocephaleus & Capilaria & $\begin{array}{c}\text { Mixed } \\
\text { infection }\end{array}$ & \\
\hline Sex & & & & \\
Female & $9(7.2 \%)$ & $13(10.4 \%)$ & $7(5.6 \%)$ & $2(1.6) \%$ & $31(34.8 \%)$ \\
Male & $10(8 \%)$ & $1(0.8 \%)$ & $2(1.6 \%)$ & $3(2.4 \%)$ & $16(12.8 \%)$ \\
Total & $19(15.2 \%)$ & $14(11.2 \%)$ & $9(7.2 \%)$ & $5(4 \%)$ & $47(37.6 \%)$ \\
Weight (g) & & & & & \\
$<500$ & $3(2.4 \%)$ & $1(0.8 \%)$ & $4(3.2 \%)$ & $0(0.00 \%)$ & $8(6.4 \%)$ \\
$500-1000$ & $16(12.8 \%)$ & $12(9.6 \%)$ & $5(4 \%)$ & $5(4 \%)$ & $38(30.4 \%)$ \\
$>1000$ & $0(0.00 \%)$ & $1(0.8 \%)$ & $0(0.00 \%)$ & $0(0.00 \%)$ & $1(0.8 \%)$ \\
Total & $19(15.2 \%)$ & $14(11.2 \%)$ & $9(7.2 \%)$ & $5(4 \%)$ & $47(37.6 \%)$ \\
\hline * -value $=0.00$. & & & & &
\end{tabular}

Lastly, the distribution of the individual parasites in relation to the standard and total lengths of the infected fish species showed a statistically significant variation in the distribution of parasites of specific genera with respect to the lengths of the sampled fish (Table 5).

Table 5. Association between the distributions of parasite genera with the lengths of the examined fish species from Lake Hashenge.

\begin{tabular}{lccccc}
\hline $\begin{array}{l}\text { Fish Length } \\
\text { (cm) }\end{array}$ & \multicolumn{2}{l}{ Genera of Parasites } & \multicolumn{2}{l}{ Total } \\
\cline { 2 - 4 } & Clinostomum & $\begin{array}{c}\text { Acanthoc } \\
\text { ephaleus }\end{array}$ & Capillaria & $\begin{array}{c}\text { Mixed } \\
\text { infection }\end{array}$ & \\
\cline { 1 - 3 } Standard Length (cm) & & & & \\
$15-30$ & $5(4 \%)$ & $4(3.2 \%)$ & $4(3.2 \%)$ & $0(0.00)$ & $13(10.4 \%)$ \\
$>30$ & $14(11.2 \%)$ & $10(8 \%)$ & $5(4 \%)$ & $5(4 \%)$ & $34(27.2 \%)$ \\
Total & $19(15.2 \%)$ & $14(11.2 \%)$ & $9(7.2 \%)$ & $5(4 \%)$ & $47(37.6 \%)$ \\
Total Length (cm) & & & & & \\
$20-40$ & $10(8 \%)$ & $8(6.4 \%)$ & $6(4.8 \%)$ & $4(3.2 \%)$ & $28(22.4 \%)$ \\
$>40$ & $9(7.2 \%)$ & $6(4.8 \%)$ & $3(2.4 \%)$ & $1(0.8 \%)$ & $19(15.2 \%)$
\end{tabular}




\begin{tabular}{llllll} 
Total & $19(15.2 \%)$ & $14(11.2 \%)$ & $9(7.2 \%)$ & $5(4 \%)$ & $47(37.6 \%)$ \\
\hline *p-value $=0.00 \%$
\end{tabular}

\section{Socio-demographic characteristics of respondents}

Respondents of the current study were people living in and around the vicinity of Lake Hashenge and comprised of different age groups, sex, educational level, marital status and occupational status. Males accounted for $92 \%$ of the total respondents. The maximum number of the respondents $(56 \%)$ were in age group 18-40 years which are found at early adulthood and adult periods, followed by the age group $>40$ years which are from the late adult to old age accounting for $40 \%$, and the rest few $(4 \%)$ being young of $<18$ years old. Moreover, $42 \%$ of the respondents were formally educated (elementary, high school and college levels), $28 \%$ of them had informal education which means they can only read and write, and the rest (30\%) were illiterate. Furthermore, 36\% of the respondents were fishermen from the existing two fishery associations around the lake and the rest (64\%) were primarily farmers involved in cultivation of different crops and vegetables' around the lake (Table 6).

Table 6. The socio-demographic characteristics of respondents.

\begin{tabular}{lcc}
\hline Variables & Frequency(n) & Percentage (\%) \\
\hline Age & 4 & 4 \\
$<18$ & 56 & 56 \\
$18-40$ & 40 & 40 \\
$>40$ & & \\
Education Status & 42 & 42 \\
Formal education & 28 & 28 \\
Informal education & 30 & 30 \\
Illiterate & & \\
Sex & 92 & 92 \\
Male & 8 & 8 \\
Female & & \\
Occupation & 64 & 36 \\
Farmers & 36 & \\
Fishermen & & \\
\hline
\end{tabular}




\section{Respondents level of awareness}

More than $75 \%$ of the respondents have been living around the vicinity of Lake Hashenge for longer period, of which $85 \%$ of them have lived there for $>15$ years, $10 \%$ of them $10-15$ years, $3 \%$ between $5-10$ years and only $4 \%$ of them have been living for less than five years. Most of the residents of the villages around the Lake (64\%) were found to be farmers involved in cultivation of different crops and vegetables with a conjoint livestock rearing as income sources but sometimes involved in fishing for subsistence or home usage and the rest $36(36 \%)$ of the respondents were fishermen networked in association for fishing and market supply purposes.

Regarding the knowledge of the respondents on the status of the volume of water of the Lake, $64 \%$ of them believed that there is extreme reduction on the Lake's volume than before, $28 \%$ of them agree that there are small or insignificant reduction and only $8 \%$ of the respondents said that the volume of the water was not changing and it is the same as before. With regard to the decreasing status of fish production potential of the Lake, $64 \%$ of the respondents were aware about the extreme reduction in the quantity of the currently harvested fish from the Lake than before, $28 \%$ less significant reduction in the quantity and only $8 \%$ of the respondents believe that the quantity of fish produced from this lake is the same as before.

Respondents were further asked for any human related activities that pose risk to the Lake. Accordingly, all respondents (100\%) stated that activities such as washing clothes and sometimes vehicles are often practiced in the Lake's vicinity. Likewise, about $86 \%$ of the respondents have also believed that illegal fishing is practiced to some extent in the Lake. Moreover, all respondents (100\%) have also stated that the water from Lake is also used for irrigation purpose by the nearby residents, and floods from nearby uphill mountains often join the Lake.

\section{Discussion}

Fish parasites are among the most important causes hampering the productivity of the fishery sector. In the current study, helminth parasites belonging to the genera Clinostomum, Capillaria and Acanthocephalan were found in the examined fish yielding an overall prevalence of $37.6 \%$. This finding was in line

Ethiop. Vet. J., 2017, 21 (2), 75-91 
with the reports of Goselle et al (2008) who reported a prevalence of $36.9 \%$ at an agro-ecologically equivalent Lamingo Dam in western Nigeria. However, it was by far lower than previous reports of $75.67 \%$ by Zelalem Temesgen (2003) at Lake Hawassa, and $43.4 \%$ by Bichi and Ibrahim (2010) in Tilapia species in Tiga Lake, Northern Nigeria. This suggest that the distribution of fish parasites often vary from one habitat to the other due to the host-parasite relationships and the fluctuations in abiotic factors like dissolved oxygen, temperature and $\mathrm{pH}$ (Abadi Amare et al., 2014). Intolerable lower levels of dissolved oxygen (DO) are fatal for the parasite's host life, the rest biota in the aquatic ecosystem and, hence, the parasite's life by itself. Similarly, fluctuating values of water temperature and $\mathrm{pH}$ can cause thermal and acidic or alkaline deaths to the host fish or directly have an ill-effect on the parasite itself (Abadi Amare et al., 2014; Abebe Getahun et al., 2008). The effect of such abiotic factors could be due to the fact that abnormally fluctuating values of these factors can act as environmental stressors compromising the immune status of the host and thereby affect the extent of parasite distribution. Likewise, lower prevalence of $20.8 \%$ of fish parasite has also been reported by Jossy Bekele and Daniel Husien (2015) in Lake Ziway.

The higher prevalence for internal helminthes in the present study could be attributed to different factors such as absence of proper waste disposal and management system in which case post-harvest fishes were processed and the waste (scraps and gastrointestinal contents) were dumped into the Lake and its shorelines, environmental pollutions like detergents that were used during washing of cloths on the lake shore, and stress caused from the surrounding of the lake due to grazing of animals and some birds which can act as intermediate or final hosts for the parasites.

Assessments made for associated risk factors have shown a higher significant infection in female fish (34.8\%) than males (12.8\%). This corresponds to the findings of Imam and Dewu, (2010) and Bichi and Ibrahim (2010) who stated that female fish were generally more liable than males to infestations with various genera of parasites of cestodes, nematodes and trematodes. This could be due to the differences in physiological condition of females, especially the gravid ones which have resulted in reduced resistance to parasitic infections (Imam and Dewu, 2010). However, Akinsanya et al (2008) and Allumma and Idowu, (2011) have recently found that male specimens presented a higher rate of internal parasite infestation than females which completely contradicts with this finding. The finding of higher infestation rate of $O$. niloticus $(34.8 \%)$ 
than T. zilli contradicts the report of Edemma et al (2008) who have reported that all species of fish are vulnerable to various parasitic infections depending on the species of fish and the type of water body inhabited. The species difference in this study might be attributed to the random sampling of specimens made which have led to differences in number of sampled fish, which was, indeed, stated by Edemma and his co-workers (2008).

The prevalence of internal parasites was also evaluated based on the length and weight of sampled fish. Accordingly, results revealed a higher parasite infestation in longer $(>30 \mathrm{~cm})$ and large sized (500-1000g) fish classes. Similarly, Allumma and Idowu (2011) and Bichi and Ibrahim (2009) have found that larger fish were heavily parasitized than the smaller ones. The prevalence of parasite infection increased with increasing length, size and age of the fish host as it increases their chance of acquiring the parasite infection with time and increased size as well. That is, longer fish provide greater surface for infection than smaller ones (Abadi Amare et al., 2014).

The host distribution of Clinostomum spp. (15.2\%) was found to be significantly lower than previous reports of Lemma Abera (2013) as 56.20\% Clinostomum in Lake Zwai, and $47.8 \%$ in Lake Lugo. The differences could be due to the difference in the physiochemical parameters between these water bodies and that of Lake Hashenge. However, Acanthocephalans spp. were detected in the intestine of $O$. niloticus and $T$. zilli as $11.2 \%$ which was significantly higher than reports of Lemma Abera, (2013) as 2.73\% in O. niloticus in Lake Zwai. Despite of the well-structured fearsome hooked proboscis of the Acanthocephalan parasitic genera, they are generally reported as less serious pathogens of fish (Roberts, 2001).

In the present study, it has been proved by majority of the respondents (92\%) that the current quantity of water and fish population have reduced by far from its previous status indicating a future threat for the Lake. Indeed, this has been further evidenced by the observable quantity of the daily fish catch at harvest (less than 100 fishes/day). In line with the current findings, previous works carried on Lake Hashenge's fish population have documented the presence of several species of fish including the Nile tilapia, African cat fish, T. zilli and Barbus spp. at higher proportions (TBARD, 2010; Angesom et al., 2010; Lmenew Yared et al., 2009). However, only two species of fish (mainly Nile tilapia and few $T$. zilli) were sampled across the study period indicating 
the severe reduction in fish population and exhaustion of some species which in fact was also witnessed by all of the respondents (100\%).

Furthermore, it was also found that people wash their clothes and sometimes vehicles around the Lake shores using detergents and mainly the toxic plant Phytolaca dodecanda 'Endod' which are reported to cause a lethal effect on the fish population and entire ecosystem as well. In line with this finding, it has been reported that species and habitat degradation due to pollution of the freshwater environment can be induced by different factors including dis-charges from factories, washing activities, and sewage (Abebe Getahun et al., 2008; FAO, 2014).

Respondents have also stated that they often use the Lake's water for irrigation purposes of the surrounding small plots of land. Agreeably, unmanaged irrigation has been reported to cause habitat degradation of the aquatic system. As it has been described by Abebe Getahun et al (2008) and Tadesse Alemayehu et al (2009), in Ethiopia there has been a great increase in the extent of irrigation schemes in recent years. Water is being removed directly from the lakes and/or diverted from rivers that feed the lakes. This has created considerable water level declines in several of the Rift Valley Lakes like Ziway and Abijata which has damaged the breeding grounds of fish species that spawn in shallow parts of the Lakes, such as Nile tilapia, causing reduced tilapia stocks (Zinabu Gebremariam, 2002; Wassie Anteneh et al., 2008). Furthermore, the current study has also shown that there are seasonal running waters from mountains eroding soils and feeding the Lake. In agreement with this finding, Mohammed and his coworkers (2009) and Eshete Dejen (2008a) have stated that increased soil erosion often brings excess sediment load and causes low oxygen content and mud cover on the gravel beds in the inflowing rivers and wetlands and flood plains are converted to agriculture seriously affecting the recruitment of several endemic aquatic species and threatens the biodiversity of Lake Tana.

With regard to the fish harvesting practice of Lake Hashenge, respondents have mentioned that fishing is done by networked groups of authorized fishermen associations through an over nightly stretched gillnets where harvesting is done early in the morning. However, it was stated that there are illegal fishing activities (86\%) being practiced in the Lake and illegal sells along streets across the Lake leading to overfishing and miss management in the fishing activity. In agreement with this finding, it has been stated that before 15-20 
years, Nile perch used to contribute about $20 \%$ of the total fish landings from Lakes Abaya and Chamo, however, through time this has reduced to a very small proportion due to overfishing and the lack of proper fisheries manage-ment. Generally, inadequate legal and policy frameworks have in fact largely given rise to poor fishery resource exploitation resulting in overfishing of some important species, such as the Nile perch in Lake Chamo, and Tilapia in Lakes Hawassa and Ziway (Eshete Dejen, 2008b; FAO, 2014).

In conclusion, high occurrence of fish internal parasites was recorded in Lake Hashenge. Moreover, parasites were found to significantly affect or reduce the body weight and length/size of the fish, and of which the effect was higher in female population. The use of detergents for washing clothes, the practice of unmanaged irrigation near the shore of the lake, and illegal fishing activities were among the human-associated causes for fish population reduction and/or exhaustion in the Lake. In general, the contribution of the nearby dwellers to the lake management was very poor due to lack of knowledge and aware-ness on the proper use and management of the lake. Hence, a future focus and stretch of intervention-based programs for alleviation of the problems before its exhaustion is paramount.

\section{References}

Abay, H., and Kebede, E. 2007. A Preliminary Study of Fish Parasites at Lake Hash- enge, Northern Ethiopia. A DVM Thesis, College of Veterinary Medicine, Addis Ababa University, Debre zeit, Ethiopia. Pp. 12-29.

Abera, L. 2013. Study on temporal variation of internal fish parasites in Lake Zewai, Ethiopia. Afri. J. Fish. Sci., 1, 1-4

Akinsanya, B., Hassan, A.A., Adeogun, A.O., 2008. Gastrointestinal helminth parasites of the fish Synodontis clarias, from Lake Lagoon, Lagos, Nigeria. Int. J. Trop. Biol., 56, 2021-2026.

Alemayehu, T., McCartney, M. and Kebede, S., 2009. Simulation of water resource development and environmental flows in Lake Tana Sub-basin. International Water Management Institute, Colombo, Sri Lanka, IWMI Research Report 134, p. 39.

Allumma, M.I., Idowu, R.T., 2011. Prevalence of Gill helminthes of Clarias gariepinus in Baga side of Lake Chad. J. Ap. Sci. Enviro. Manag.15, 47-50.

Amare, A., Alemayehu, A., Aylate, A., 2014. Prevalence of Internal Parasitic Helminthes Infecting Oreochromis niloticus, Clarias gariepinus, and Cyprinus carpio in Lake Lugo, Northeast Ethiopia. J. Aqu. Res. Dev. 5, 233. 
Anteneh, W., Getahun, A. and Dejen, E., 2008. The spawning migration of Labeobarbus species of Lake Tana to Ribb River. J. Ethiop. Fish. Aqu. Sci. Assoc., 4, 22-30.

Asgedom, A.G., Desta, M.B., and Gebremedhn, Y.W., 2012. Bioaccumulation of Heavy Metals in Fishes of Hashenge Lake, Tigray, Northern Highlands of Ethiopia. Am. J. Chem., 2, 326-334.

Bekele, J., Hussien, D., 2015. Prevalence of Internal Parasites of Oreochromis niloticus and Clarias gariepinus Fish Species in Lake Ziway, Ethiopia. J. Aqu. Res.Dev., 6, 308. doi:10.4172/2155-9546.1000308

Bichi, A.H., Ibrahim, A.A., 2009. A survey of ecto- and intestinal parasites of Tilapia zilli (Gervias) in Tiga Lake, Kano, Northern Nigeria. J. Pure. Appl. Sci., 2, 79-82.

Dejen, E., 2008a. Wetlands and fishery resources: the impact of wetland degradation on fishery resources. Wetland Policy and Strategy Development in Ethiopia, Pp. 60-71.

Dejen, E., 2008b. Observation on parasites of Tilapia nilotica and Claries mossambicus, at Lake Awassa, Ethiopia. J. Agri. Sci., 2,126-130.

Edemma, M.O. Ntengwe, F.W. and Idowu A.B. 2008. Physico-chemical and microbiological characteristics of water for fish production using small ponds. Phys. and Chem. Ear., 33, 701-707.

FAO, 2014. Fishery country profile, Ethiopia. Available at http://www.Fao.org /fi/ oldsite /FCP/en/ETH/profile.htm., accessed on: 21 November, 2016.

Gebremariam, Z., 2002. The Ethiopian Rift Valley lakes: Major threats and strategies for conservation. In: C. Tudorancea \& W.D. Taylor (Eds.) Ethiopian Rift Valley Lakes. Biology of Inland Waters Series, Backhuys Publishers, Leiden, the Nether-lands, Pp. 259-271.

Getahun, A., Dejen, E. \& Anteneh, W., 2008. Fishery studies of Ribb River, Lake Tana basin, Ethiopia. Ethiopian Nile Irrigation and Drainage Project Coordination Office, Ministry of Water Resources, Final Report, 2, 1573.

Goselle, O.N., Shir, G.I., Udeh, E.O., Abelau, M. \& Imandeh, G.N., 2008. Helminth Parasites of Clarias Gariepinus and Tilapia Zilli at Lamingo Dam. Applied Entomology and Parasitology Unit, Department of Zoology, University of Jos, Nigeria,2.4

Gulelat, Y., Eshetu, Y., Asmare, K., Bekele, J., 2013. Study on Parasitic Helminthes Infecting Three Fish Species from Koka Reservoir, Ethiopia. SINET: Ethiop. J. Sci., 36, 73-80.

Imam, T.S., Dewu, R. A., 2010. Survey of piscine ecto- and intestinal parasites of clarias species sold at Galadima Road fish market, Kano metyropolis, Nigeria. Biosci. Res. Commun., 22, 209-214. 
Mitike, A. 2014. Fish Production, Consumption and Management in Ethiopia. Res. J. Agri. Env. Manag. 3, 460-466.

Kayis, S., Ozcelep, T., Capkin, E. and Altinok, I. 2009. Protozoan and metazoan parasites of cultured fish in Turkey and their applied treatments. The Israeli J. of Aqu. Bamidgeh 61, 93-102.

MOA, 2015. Annual production of fish in the country. Unpublished report of the Ministry of Agriculture, Federal Democratic Republic of Ethiopia, Addis Ababa, Ethiopia, Pp. 16-29.

Mohammed, B., de Graaf, M., Nagelkerke, L.A.J., Mingist, M. \& Anteneh, W., 2009. Lake Tana's (Ethiopia) endemic Labeobarbus species flock: An uncertain future threatened by exploitation, land use and water resource developments. In: Proceedings of the Ethiopian Fisheries and Aquatic Sciences Association (EFASA) Meeting, Haramaya University, Dire dawa, Ethiopia.

Paperna, I., 1980. Parasites infections and diseases of fish in Africa. CIFA Technical Paper. FAO Publication, 7, 21.

Roberts, R.J., 2001. Fish Pathology (3rd ed.) Technical Director, Landa catches Ltd. Scotland, Pp. 270-300.

Rothuis, A., van Duijn, A.P., Dejen, E., Kamstra, A., van der Pijl, W., Rurangwa, E., Stokkers, R., 2012. Business opportunities for aquaculture in Ethiopia. LEI report, Wageningen UR, The Hague, Pp. 55-87.

TBARD, 2010. Tigray Bureau of Agriculture and Rural Development. "Annual report" for Ofla Wereda Agriculture and Rural Development office, Korem, Tigray, Ethiopia. Pp. 67-81.

Temesgen, Z., 2003. Study on parasite of fish at Lake Awassa. DVM thesis, Addis Ababa University, Faculty of Veterinary Medicine, Debre Zeit, Ethiopia, Pp. 12-18.

Thrusfield, M., 2005. Veterinary Epidemiology (3rd ed.).Blackwell Science Ltd, UK. Pp. 233-250.

Tizie, E., Baye, D., Mohamed, A., 2014. Prevalence of Ligula intestinalis Larvae in Barbus Fish Genera at Lake Tana Ethiopia. World J. Fish \& marine Sci., 6, 408-416.

Urquhart, G.M., Armour, J., Duncan, J.L., Dunn, A.M., Jennings, F.W., 2003. Veterinary parasitology ( $3^{\text {rd }}$ ed.), The Faculty of Veterinary Medicine, the University of Glasgow, Scotland, Pp. 100-12.

Yared, L. 2009. Reducing Postharvest Fish Loses in Selected Lakes of Ethiopia. Project report of the NAHDIC research center, Sebeta, Ethiopia, Pp. 1-44.

Zhokhov, A.E. Tuskanna, M.J. and Mironovsky, 2007. Methods of the complete parasitological dissection of fish. Progress press, Moscow, Russia, Pp. 21-46.

Ethiop. Vet. J., 2017, 21 (2), 75-91 